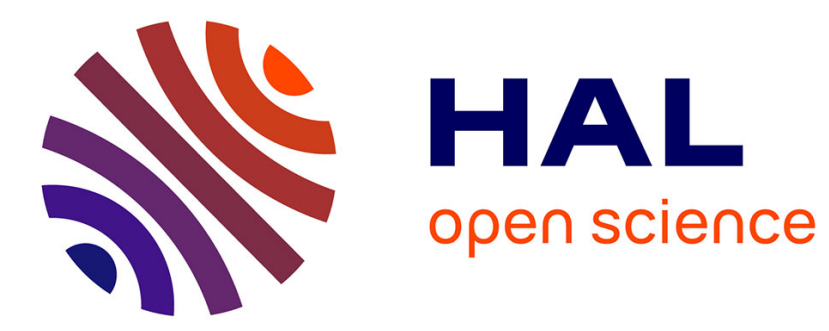

\title{
BRAIN-COMPUTER INTERFACE (BCI) LITERATURE - A BIBLIOMETRIC STUDY
}

Brahim Hamadicharef

\section{To cite this version:}

Brahim Hamadicharef. BRAIN-COMPUTER INTERFACE (BCI) LITERATURE - A BIBLIOMETRIC STUDY. 10th International Conference on Information Science, Signal Processing and their applications (ISSPA2010), May 2010, Kuala Lumpur, Malaysia. pp.626-629. inria-00511189

\section{HAL Id: inria-00511189 \\ https://hal.inria.fr/inria-00511189}

Submitted on 24 Aug 2010

HAL is a multi-disciplinary open access archive for the deposit and dissemination of scientific research documents, whether they are published or not. The documents may come from teaching and research institutions in France or abroad, or from public or private research centers.
L'archive ouverte pluridisciplinaire HAL, est destinée au dépôt et à la diffusion de documents scientifiques de niveau recherche, publiés ou non, émanant des établissements d'enseignement et de recherche français ou étrangers, des laboratoires publics ou privés. 


\title{
BRAIN-COMPUTER INTERFACE (BCI) LITERATURE - A BIBLIOMETRIC STUDY
}

\author{
Brahim Hamadicharef \\ Tiara \#22-02 \\ 1 Kim Seng Walk \\ Singapore 239403
}

\begin{abstract}
Brain-Computer Interface (BCI) is a relatively young research field which has seen a growing interest with associated number of publications over the last two decades. In this study we present the first bibliometric analysis of the BCI literature (1990-2008) from the Thomson Reuters's Institute for Scientific Information (ISI) Web of Knowledge. Thus, the main objectives of this bibliometric study are: 1) to explore the growth of BCI literature, 2) to assess if it follows Lotka's law of scientific productivity, 3) to identify authors, groups and countries contributing the most to BCI, 4) to reveal the characteristic of citation for the BCI literature, and finally, 5) to determine the core journals that published substantial portions of the literature on BCI. Results indicate that BCI literature follows a power law growth, has an average author count of 3.9 and an average page count of 7.09. More than half (52.73\%) of the BCI literature is never cited, and 14 papers have been cited more than 100 times. The 3 most productive authors are leading BCI research groups, in Austria, Germany and the USA.
\end{abstract}

\section{INTRODUCTION}

Brain-Computer Interface (BCI) is a relatively recent research field which has witnessed a growing number of publications over the last two decades. Still to provide a clear view of the current state-of-the-art and who are the eminent authors in the field, there is yet no such scientometric or bibliometric study.

In a nutshell, BCI, also named Brain-Machine Interface (BMI) when using invasive EEG [5], allows by means of Electroencephalogram (EEG) to communicate (for e.g. word spelling) and control external devices, for example a wheelchair. Recently it has found new applications in stroke rehabilitation, as new paradigm for assistive medical devices, helping to improve people's quality of life in their daily activities, and even gaming [18].

After nearly two decades of research and development in BCI, a bibliometric analysis is timely to study the field. Thus, the main objectives of this bibliometric study are: 1) to explore the growth of BCI literature, 2) to assess if it follows Lotka's law of scientific productivity, 3) to identify authors, groups and countries contributing the most to BCI, 4) to reveal its citation characteristic, and finally, 5) to determine the core journals that published substantial portions of the literature on BCI.

The remainder of this paper is organized as follows. In Section 2, the bibliometric analysis methodology is presented. In Section 3, we present results based on a large BCI citation database from 1990 to 2008 . Finally, in Section 4 , we conclude the paper.

\section{METHODOLOGY}

We created a database of the BCI literature using Thomson Reuters's Institute for Scientific Information (ISI) Web of Knowledge ${ }^{1}$. The search, using the topic term 'BrainComputer Interface', was limited to the period from 1990 to 2008. Yearly record provides the publication title, authors' names, journal details, page count, number of times the publication was cited, etc. In total, 1081 publications were retrieved for this bibliometric study.

\section{RESULTS}

\subsection{Growth of BCI Literature}

Figure 1(a) shows the BCI publications count evolution on a yearly basis. Not shown in the ISI records, the earliest paper describing a BCI system was published in 1973 by J. J. Vidal [12]. Two decades later, pioneer BCI research by J. Wolpaw was first published in 1990 [15] and 1991 [17], followed by small numbers of papers in the 90's. This grew substantially since 2003, augmenting to 92 in 2003, to 171 in 2006, to 217 in 2007, and 280 in 2008. One could speculate that the BCI competitions (first organized in 2001, then 2003, 2005 and more recently in 2008) have helped to sustain such rate of growth.

Of the 1081 publications, 586 were published in 178 journals and 495 were published in conference proceedings. On average, 57 publications have been published each year by 230 authors. The average is 3.9 authors per paper, page count of 7.06, and papers are cited on average 38.43 times (per year). Clearly after 2001, publications counts has steadily increased every year. We plot the cumulative count of BCI literature in Figure 1(b). The cumulative count follows a power law model, defined as:

$$
C=\beta Y^{\alpha}
$$

\footnotetext{
${ }^{1}$ www.isiknowledge.com
} 


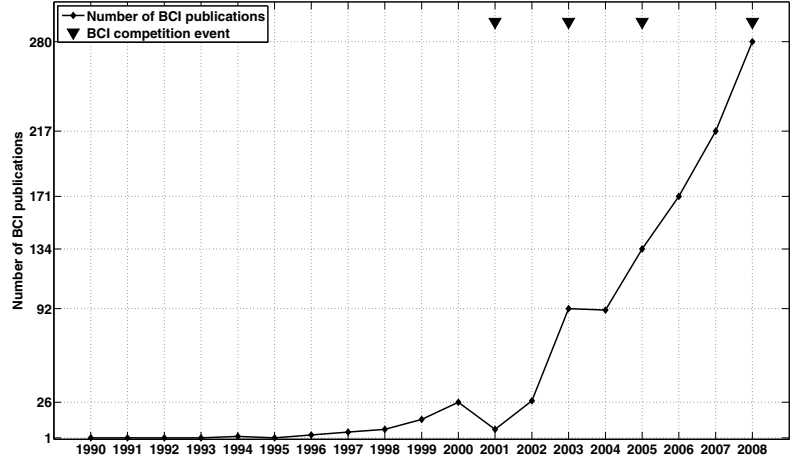

(a)

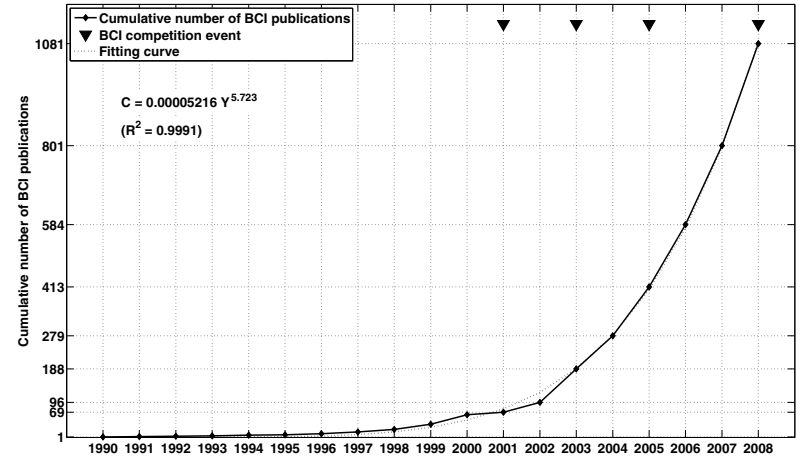

(b)

Fig. 1. BCI literature: a) Growth and b) Cumulative count

where $C$ is the cumulative number of BCI publications and $Y$ is the number of years since 1990 . Using the curve fitting tool from MATLAB to estimate $\beta$ and $\alpha$, we obtained $\beta=0.00005216$ and $\alpha=5.723$, with a goodnessof-fit $R^{2}=0.9991$.

\subsection{Authorship Pattern}

From the 4355 authors who wrote the 1081 publications, 1808 are unique authors. About $1120(25.71 \%)$ authors have only one publication and $293(6.72 \%)$ authors have two publications. Lotka's law [6], an inverse square law, was used to find authors productivity patterns. It typically states that for every 100 authors contributing to one article, 25 will contribute 2, 11 will contribute 3 , etc. (i.e. $1 / n^{2}$ ). According to Lotka's law of scientific productivity, only $6 \%$ of the authors in the field will produce more than 10 articles. The general form of Lotka's law is defined as:

$$
y=C / x^{n}
$$

where $x$ is the number of contributing authors and $y$ is the number of publications. The exponent $n$ and constant $C$ are estimated, respectively, by linear least square fitting and an approximation function [9]. We find $n=1.8552$ and $C=0.5540$. Figure 2 shows the Log-Log plot of the number of author and their corresponding number of publications. Using the Kolmogorov-Smirnov test (KS-test) of goodness-of-fit we find that the null hypothesis that the BCI literature conforms to Lokta law must be rejected at 0.01 level of significance.

\subsection{Most Productive BCI Authors}

The list of the 30 most productive BCI authors, with in '()' their number of publications referred in the ISI database, is as follows: Gert Pfurtscheller (95), Niels Birbaumer (63), Jonathan Wolpaw (55), Dennis McFarland (43), Gerwin Schalk (36), Xiaorong Gao (34), Gary Birch (33), Christa Neuper (28), Benjamin Blankertz (29), Shangkai Gao (29), Andrea Kubler (28), Cuntai Guan (26), Reinhold Scherer (26), Thilo Hinterberger (25), Klaus-Robert Muller (25), Gabriel Curio (23), Theresa Vaughan (23), Maria Marciani (22), Febo Cincotti (18), Fabio Babiloni

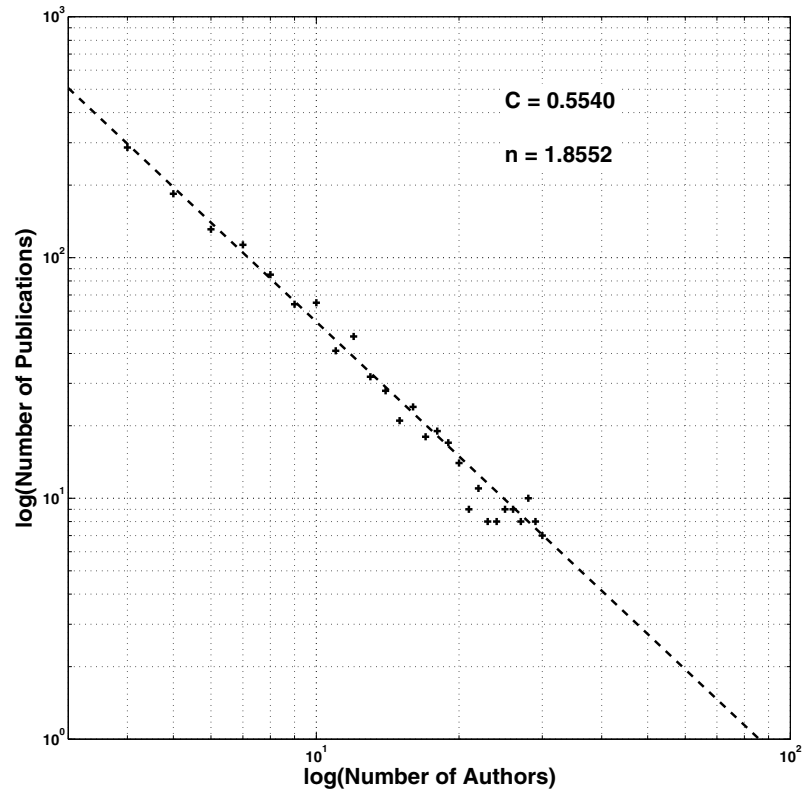

Fig. 2. Log-Log plot of the number of author and the number of publications

(17), Christoph Guger (17), Steven Mason, (17), Alois Schlögl (17), Luigi Bianchi (16), Guido Dornhege (16), Bin He (16), Bo Hong (16), Dean Krusienski (16), Rabab Ward (16), Haihong Zhang (19).

G. Pfurtscheller, N. Birbaumer and J. Wolpaw are clearly the most productive authors in BCI research, each leading BCI research group, respectively, at Graz University of Technology (Austria), the University of Tübingen (Germany), and the Wadsworth Center (New York, USA).

\subsection{Citation pattern}

The citation pattern distribution of the BCI literature is shown in Figure 3. It shows that more than half $(52.73 \%)$ of BCI publications is never cited, $12.77 \%$ cited between 3 and 10 times, $15.17 \%$ cited between 11 an 50 times, and that top BCI articles (1.3\%) are cited more than 100 times. Cited 623, 262, 222, 195, 185, 182, 174, 163, 130, 104, 103, 101 and 101 times, respectively, the top cited 


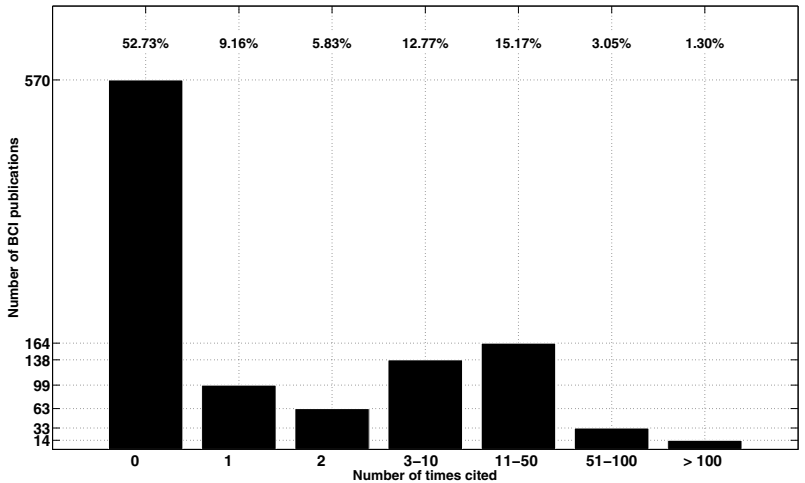

Fig. 3. Citation pattern of BCI literature



Fig. 4. Bradford curve showing journal rank (log scale) versus number of publications

BCI papers are the following: [18],[3],[13],[17],[2],[19], [14],[4],[10],[8],[16],[1],[11].

\subsection{BCI Core Journals}

The Bradford's law was used to find the BCI core journals using the 586 articles published in 178 journals. The Bradford curve, as shown in Figure 4, shows the journal rank (log scale) versus its number of publications, showing that there are 10 core journals (as listed in Table 1). IEEE Transactions on Neural Systems and Rehabilitation Engineering published 92 articles $(8.51 \%$ of the total BCI literature), followed by IEEE Transactions on Biomedical Engineering with 55 articles (5.09\%). The top $10 \mathrm{BCI}$ core journals account for $28.41 \%$ of the total BCI literature, with impact factor varying from 0.888 (Biomedizinische Technik) to 5.694 (NeuroImage) and a mean of 2.5215. Notice that journal Transactions on Neural Systems and Rehabilitation Engineering (\#1) is the continuation of Transactions on Rehabilitation Engineering (19932000)(\#6) journal.

\section{CONCLUSION}

In this paper we presented the first bibliometric study of the BCI literature. Using the ISI Web of Knowledge, we searched publication records from 1990 to 2008 . The study revealed the following. A total of 1081 publications were retrieved with 495 published in conference proceedings and 586 published in 178 journals, with an average of 3.9 authors per paper. The cumulative publication count follows a power law model, with significant growth since 2001. Surprisingly $52.73 \%$ of the BCI literature is never cited, 14 key articles have been cited more than 100 times. We find that the BCI literature does not follow Lotka's law (verified by KS-test). G. Pfurtscheller, N. Birbaumer and J. Wolpaw are the most productive authors. The top two journals to publish BCI research are the IEEE Transactions on Neural Systems and Rehabilitation Engineering and IEEE Transactions on Biomedical Engineering.

The list of most productive authors will serve as the basis for an Author Co-citation Analysis (ACA) [7] to study author's relationship within the BCI research space.

\section{REFERENCES}

[1] B. Blankertz, K.-R. Müller, G. Curio, T. Vaughan, G. Schalk, J. R. Wolpaw, A. Schlögl, C. Neuper, G. Pfurtscheller, T. Hinterberger, M. Schröder, and N. Birbaumer, "The BCI competition 2003: Progress and perspectives in detection and discrimination of EEG single trials," IEEE Transactions on Biomedical Engineering, vol. 51, no. 6, pp. 1044-1051, June 2004.

[2] E. Donchin, K. M. Spencer, and R. Wijesinghe, "The mental prosthesis: Assessing the speed of a P300 based brain-computer interface," IEEE Transactions on Rehabilitation Engineering, vol. 8, no. 2, pp. 174-179, June 2000.

[3] L. R. Hochberg, M. D. Serruya, G. M. Friehs, J. A. Mukand, M. Saleh, A. H. Caplan, A. Branner, D. Chen, R. D. Penn, and J. P. Donoghue, "Neuronal ensemble control of prosthetic devices by a human with tetraplegia," Nature, vol. 442, no. 7099, pp. 164-171, March 2006.

[4] P. R. Kennedy, R. Bakay, M. M. Moore, K. Adams, and J. Goldwaithe, "Direct control of a computer from the human central nervous system," IEEE Transactions on Rehabilitation Engineering, vol. 8, no. 2, pp. 198-202, June 2000.

[5] M. A. Lebedev and M. A. L. Nicolelis, "Brainmachine interfaces: Past, present and future," Trends in Neurosciences, vol. 29, no. 9, pp. 536-546, September 2006.

[6] A. J. Lotka, "The frequency distribution of scientific productivity," Journal of the Washington Academy of Sciences, vol. 16, no. 12, pp. 317-324, 1926. 
Table 1. Core journals publishing BCI literature

\begin{tabular}{|c|c|c|c|c|c|c|}
\hline Rank & Name of the journal & NP & $\%$ & IF & $\mathrm{PF}$ & Publisher \\
\hline$\# 1$ & $\begin{array}{l}\text { IEEE Transactions on Neural Systems } \\
\text { and Rehabilitation Engineering }\end{array}$ & 92 & 8.51 & 2.700 & 4 & IEEE \\
\hline$\# 2$ & IEEE Transactions on Biomedical Engineering & 55 & 5.09 & 1.398 & 12 & IEEE \\
\hline \#3 & Clinical NeuroPhysiology & 32 & 2.96 & 2.972 & 12 & Elsevier \\
\hline \#4 & Journal of Neural Engineering & 31 & 2.87 & 2.737 & 4 & IOP \\
\hline \#5 & Journal of NeuroScience Methods & 26 & 2.41 & 2.092 & 18 & Elsevier \\
\hline \#6 & IEEE Transactions on Rehabilitation Engineering & 17 & 1.57 & 2.036 & 4 & IEEE \\
\hline \#7 & Medical \& Biological Engineering \& Computing & 17 & 1.57 & 1.379 & 12 & Springer \\
\hline \#8 & PsychoPhysiology & 16 & 1.48 & 3.318 & 6 & Wiley \\
\hline \#9 & Biomedizinische Technik & 11 & 1.02 & 0.889 & 6 & Walter de Gruyter \\
\hline$\# 10$ & NeuroImage & 10 & 0.93 & 5.694 & 20 & Elsevier \\
\hline
\end{tabular}

NP: number of publications, IF: impact factor, PF: publication frequency (issues/year)

[7] K. W. McCain, "Mapping authors in intellectual space: A technical overview," Journal of the American Society for Information Science, vol. 41, no. 6, pp. 433-443, September 1990.

[8] D. J. McFarland, L. M. McCane, S. V. David, and J. R. Wolpaw, "Spatial filter selection for EEG-based communication," Electroencephalography and Clinical Neurophysiology, vol. 103, no. 3, pp. 386-394, September 1997.

[9] M. L. Pao, "Lotka's law: A testing procedure," Information Processing \& Management, vol. 21, no. 4, pp. 305-320, 1985.

[10] H. Ramoser, J. Müller-Gerking, and G. Pfurtscheller, "Optimal spatial filtering of single trial EEG during imagined hand movement," IEEE Transactions on Rehabilitation Engineering, vol. 8, no. 4, pp. 441-446, December 2000.

[11] G. Schalk, D. J. McFarland, T. Hinterberger, N. Birbaumer, and J. Wolpaw, "BCI2000: A generalpurpose, brain-computer interface (BCI) system," IEEE Transactions on Biomedical Engineering, vol. 51, no. 6, pp. 1034-1043, June 2004.

[12] J. J. Vidal, "Toward Direct Brain-Computer Communication," Annual Review of Biophysics and Bioengineering, vol. 2, pp. 157-180, June 1973.

[13] J. R. Wolpaw, N. Birbaumer, W. J. Heetderks, D. J. McFarland, P. H. Peckham, G. Schalk, E. Donchin, L. A. Quatrano, C. J. Robinson, and T. M. Vaughan, "Brain-computer interface technology: A review of the first international meeting," IEEE Transactions on Rehabilitation Engineering, vol. 8, no. 2, pp. 164-173, June 2000.

[14] J. R. Wolpaw and D. J. McFarland, "Control of a two-dimensional movement signal by a noninvasive brain-computer interface in humans," Proceedings of the National Academy of Sciences (PNAS), vol. 101, no. 51, pp. 17 849-17 854, December 2004.

[15] J. R. Wolpaw, D. J. McFarland, and G. W. Neat, "Development of an Electroencephalogram-based Brain-Computer Interface," Annals of Neurology, vol. 28, no. 2, pp. 250-251, August 1990.

[16] J. R. Wolpaw, D. J. McFarland, and T. M. Vaughan, "Brain-computer interface research at the Wadsworth Center," IEEE Transactions on Rehabilitation Engineering, vol. 8, no. 2, pp. 222-226, June 2000.

[17] J. R. Wolpaw, D. McFarland, G. Neat, and C. Forneris, "An EEG-based brain-computer interface for cursor control," Electroencephalography and clinical Neurophysiology, vol. 78, no. 3, pp. 252-259, March 1991.

[18] J. R. Wolpaw, N. Birbaumer, D. J. McFarland, G. Pfurtscheller, and T. M. Vaughan, "Braincomputer interfaces for communication and control," Clinical Neurophysiology, vol. 113, no. 6, pp. 767-791, June 2002.

[19] J. R. Wolpaw and D. J. McFarland, "Multichannel EEG-based brain-computer communication," Electroencephalography and Clinical Neurophysiology, vol. 90, no. 6, pp. 444-449, June 1994. 